\title{
Ocakta tohum sayısının körpe mısır verimine ve bazı özelliklerine etkisi
}

\section{Burhan KARA $^{1}$}

1Isparta Uygulamalı Bilimler Üniversitesi, Tarım Bilimleri ve Teknolojileri Fakültesi

Alınıș tarihi: 28 Ocak 2019, Kabul tarihi: 22 Nisan 2019

Sorumlu yazar: Burhan KARA, e-posta: burhankara@isparta.edu.tr

\section{Öz}

Araștırma; ocakta tohum sayısının körpe misır verimine ve bazı özelliklerine etkisini araştırma amacıyla yürütülmüştür. Birim alandan daha fazla sayıda körpe koçan elde etmek için "Baharcin" cin mısır çeşidi kullanılarak $70 \mathrm{~cm}$ x $18 \mathrm{~cm}$ mesafede her ocağa $1,2,3,4,5$ ve 6 tohum ekilmiştir. Deneme tesadüf blokları deneme desenine göre üç tekerrürlü olarak 2017 ve 2018 yıllarında Isparta koşullarında yürütülmüştür. Körpe koçan hasadı koçan püskülü çıkışından itibaren 3. günde yapılmıştır. Her iki yılda da körpe koçan çapı (ikinci yıl hariç), körpe koçan sayısı ve verimi istatistiksel olarak önemli olmuştur. 2017 ve 2018 yıllarında, en uzun körpe koçan boyu (11.60 mm ve $11.45 \mathrm{~mm}$ ) ve en kalın körpe koçan çapı (15.10 mm ve $14.45 \mathrm{~mm}$ ) ocakta bir tohum ekilen uygulamada ölçülürken, bu özelliklerin en küçük değerleri ocakta 6 tohum ekiminde belirlenmiştir. Körpe koçan sayısı ve verimi ocaktaki tohum sayısına göre değişmiş, en yüksek koçan sayısı (26492.7 ve 26224.0 adet da $^{-1}$ ) ve körpe koçan verimi (593.07 ve $626.8 \mathrm{~kg} \mathrm{da}^{-1}$ ) her iki yılda da ocakta altı tohum ekilen parsellerde belirlenmiștir. Çalışma sonucuna göre, daha yüksek körpe koçan verimi ve koçan sayısından dolayı ocağa 5-6 tohum ekimi önerilmektedir.

Anahtar kelimeler: Ekim sıklığı, körpe koçan sayısı, verim

Effect on baby corn yield and some characteristics of seed per plot

\footnotetext{
Abstract

Research was conducted with aim to investigate the effects on baby corn yield and some characteristics of per seed bed. "Baharcin" popcorn cultivar was
}

sown 1, 2, 3, 4, 5 and 6 seeds per seed bed in $70 \mathrm{~cm} \mathrm{x}$ $18 \mathrm{~cm}$ row space for the higher baby corn number from unit area. Experiments were set up according to a randomized complete block design with three replications under 2017 and 2018 years in Isparta condition. Baby corns were harvested in $3^{\text {rd }}$ day from ear silk-out time. The differently between baby corn ear diameter (except for second year), baby corn number and yields were statistically significant. The longest baby corn ear length $(11.60 \mathrm{~mm}$ and 11.45 $\mathrm{mm})$, and the highest ear diameter $(15.10 \mathrm{~mm}$ and $14.45 \mathrm{~mm}$ ) were measured in one seed per bed, the lowest value of these characteristic were measured in six seed per bed in 2017 and 2018 years. Baby corn number and baby corn yield increased depending on increasing seed number per seed bad. The highest baby corn number (26492.7 and 26224.0 ear da $^{-1}$ ) and baby corn yield (593.07 and $626.8 \mathrm{~kg} \mathrm{da}^{-1}$ ) were determined in six seed per bed in both years. As a result of study, it has been recommended to 5-6 seed per bed due to the higher baby corn yield and baby corn number.

Key words: Sowing density, baby ear number, yield

\section{Giriş}

Döllenmemiş yumurtalıklar topluluğu olarak ta adlandırılan körpe koçan, genellikle taze olarak tüketilmekte olup, sandviç, çorbalarda, pizzalarda, pirinç biryani, süslü gevrek, sebze salatalarında, kızartılmış şekilde, turşu olarak, mısır pakora, mısır bajji ve shoup-suay (Çin yemeği) yapımında kullanılmaktadır (Satyanarayana, 1997; Najeeb ve ark., 2011). Körpe koçan düşük kalorili, nişasta içermeyen bir sebze olup, kalori bakımından brokoli, yeşil fasulye ve karnabahara benzerdir. Ayrıca körpe koçan protein, ham selüloz, karbonhidrat ve lif 
içeriği fazla olup, sindirilebilirliği yüksek bir besin maddesidir (Hooda ve Kawatra, 2013).

Körpe koçanın çeşit seçiminde; koçanın bitkiden kolay kopması, yapraklarının kolay ayrılıyor olması, bitki boyu, erkencilik ve bitkide koçan sayısı göz önünde bulundurulmaktadır. Körpe koçan erken dönemde hasat edildiği için birim alan verimi düşüktür. Dolayısıyla geleneksel misır yetiştiriciliğinden elde edilen taze koçan ve tane verimi ile karşılaştırıldığında ekonomik değer olarak daha düșük kalabilir. Körpe koçanın pazarlaması koçan sayısı üzerinden yapıldığından dolayı birim alandaki koçan sayısı birim alandaki koçan veriminden daha önemlidir. Birim alandaki koçan sayısı artırılarak ekonomik olarak daha kârlı körpe koçan üretimi yapılaması mümkündür. Bunun için çeşidin çok koçanlı olması tercih edilmektedir (Wang, 2009). Dünyada körpe koçan için özel sslah edilmiş çeșitlerde mevcut olsa da, ülkemizde henüz ıslah edilmiş bir çeşit yoktur. Birim alandan daha yüksek koçan sayısı için ekim sıklığı daha sık tutulmalıdır, ya da ekim yöntemlerini değiştirerek birim alandaki koçan sayısı artırılabilir. Ayrıca kardeşlenme özelliği olan şeker mısırda koçan bağlayan kardeşlerden ve 2-3 koçan bağlayan çeşitlerin 2. ve 3. koçanları koparılarak körpe koçan olarak değerlendirip (Kara ve ark., 2018), böylece birim alandan daha fazla koçan elde etme yoluna gidilebilir.

Tayland tarımsal standartlarına göre (ThaiAgriculturalStandard-TAS 1504-2007), kalite bakımından körpe koçanlar üç sınıfta değerlendirilmektedir (Anonim, 2014). a- "Ektra" sınıf: Süper kalite olarak pazarlanmaktadır. Körpe koçan uzunluğu 9.0-13.0 cm, tabanı düz kesilmiş, koçan yaprağı, sapı ve püsküllerden iyice temizlenmiş, koçan kusurları \%0 olmalıdır. b- Sınıf I: İyi kalite olarak pazarlanmaktadır. Körpe koçan uzunluğu 7.0-8.9 cm, tabanı düz kesilmiş, koçan yaprağı, sapı ve püsküllerden iyice temizlenmiş iyi bir görünüme sahip olması ve toplam koçan kusurları \%5'i geçmemelidir. c- Sınıf II: Körpe koçan uzunluğu 4.0-6.9 cm, koçan üzerinde sürtme, çizilme ve diğer mekanik zararlar olmamal, toplam koçan kusurları \%10'u geçmemelidir. Bu kalite sınıflarına göre körpe koçanların pazarlaması yapılmaktadır. Bu araştırma; cin mısırında birim alandan daha çok sayida körpe koçan elde etmek için ocakta tohum sayısının artırılmasının etkisini araştırmak amacıyla yürütülmüştür.

\section{Materyal ve Yöntem}

Araştırma, Isparta koşullarında, 2017 ve 2018 yıllarında tesadüf blokları deneme desenine göre 3 tekerrürlü olarak yürütülmüştür. Diğer mısır alt türlerine göre daha kısa boylu, ince gövdeli ve sık ekime daha uygun olan "Baharcin" cin mısır çeşidi kullanılmıştır.

Denemenin yürütüldüğü Isparta il merkezi, Batı Akdeniz'in yaylası olarak adlandırılan 1050 rakımlı olup, Akdeniz ile Orta Anadolu bölgesi arasında geçiş bölgesi olmasına rağmen karasal iklim özelliklerine sahiptir. Deneme yılları ve alanına ait iklim özellikleri Çizelge 1'de verilmiştir.

Çizelge 1. Deneme alanına ait iklim verileri*

\begin{tabular}{|c|c|c|c|c|c|c|}
\hline \multirow{2}{*}{ İklim faktörleri } & \multirow{2}{*}{ Yillar } & \multicolumn{4}{|c|}{ Aylar } & \multirow{2}{*}{ Toplam / Ortalama } \\
\hline & & Mayıs & Haziran & Temmuz & Ağustos & \\
\hline \multirow{3}{*}{ Yağış (mm) } & 2017 & 149.5 & 30.9 & 13.1 & 20.4 & 213.9 \\
\hline & 2018 & 43.3 & 36.8 & 4.0 & 13.3 & 97.4 \\
\hline & Uzun yıllar & 50.8 & 28.4 & 18.4 & 0.8 & 98.4 \\
\hline \multirow{3}{*}{$\begin{array}{l}\text { Ortalama sicaklık } \\
\qquad\left({ }^{\circ} \mathrm{C}\right)\end{array}$} & 2017 & 14.9 & 20.1 & 25.1 & 24.0 & 21.0 \\
\hline & 2018 & 16.8 & 20.3 & 24.3 & 23.7 & 21.3 \\
\hline & Uzun yıllar & 15.6 & 20.1 & 22.3 & 23.9 & 20.5 \\
\hline
\end{tabular}

*Isparta Meteoroloji istasyonundan alınmıştır.

Deneme toprağı; killi-tınlı, hafif bazik, kireç oranı yüksek ve organik madde oranı düşük yapıdadır.

Deneme, her iki yılda da Mayıs ayının ilk haftasında kurulmuştur. Denemede parsel sıra uzunluğu $5 \mathrm{~m}$ ve 4 sıra, bloklar arasında $2 \mathrm{~m}$, her parsel arasinda $1 \mathrm{~m}$ aralık bırakılmıștır. Tohumlar, $70 \mathrm{~cm} \mathrm{x} 18 \mathrm{~cm}$ mesafede, her ocağa 1, 2, 3, 4, 5 ve 6 tohum olacak şekilde 3-4 cm derinliğe elle ekilmiştir. Modern mısır tarımında her ocakta 1 bitki tercih edilmektedir. Bu nedenle ocakta bir bitki olan parsel kontrol olarak değerlendirilmiştir. Çıkıștan sonra her parselde ocakta çıkan tohum sayısı kontrol edilmiștir.

Amonyum sülfat formunda (\%21) saf olarak dekara $15.0 \mathrm{~kg}$ azotun $1 / 3$ ekimle, kalan $2 / 3$ bitki diz boyu (35-40 $\mathrm{cm}$ ) döneminde, triple süper fosfat formunda dekara $8.0 \mathrm{~kg}$ fosforun tamamı ekimle birlikte 
uygulanmıştır. Tohumlar ekimden itibaren damlama sulama sistemi ile sulanmıştır.

Körpe koçan hasadı, koçan püskülü çıkışından itibaren 3. günde (Bar-Zur ve Saadi, 1990) (yaklaşık 50-75 gün arasında) yapılmıştır. Hasattan sonra, körpe koçan boyu (cm), körpe koçan çapı (mm), körpe koçan sayısı (adet da-1) ve körpe koçan verimi (kg/da) ölçümleri yapılmıştır (Bozkurt ve Kara, 2018).

Elde edilen veriler, SAS istatistik paket programından faydalanılarak tesadüf blokları deneme desenine göre varyans analizleri yapılmış ve ortalamalar arasındaki farklılıklar LSD testine göre karşılaştırılmıştır.

\section{Sonuçlar ve Tartışma}

Araştırmada ocakta tohum sayısının körpe koçan sayısına, çapına (birinci yıl hariç) ve verimine etkisi istatistiksel olarak önemli olmuștur. Bu özellikler için yıllar arasındaki farklar istatistiksel olarak önemli olmamıştır (Çizelge 2). 2017 ve 2018 yıllarında körpe koçan boyu sırasıyla, 10.06-11.60 cm ve 10.41-11.45 cm, körpe koçan çapı sırasıyla, 13.46-15.10 mm ve 12.95-14.45 mm, körpe koçan sayısı sırasıyla, 8573.3-26492.7 adet da-1 ve 9050.726224.0 adet da $^{-1}$ ve körpe koçan verimi sırasıyla,
167.50-593.07 $\mathrm{kg}^{-1}$ ve 176.1-626.8 $\mathrm{kg} \mathrm{da}^{-1}$ arasında değişmiştir. Tüm ekim sıklıklarında körpe koçanlar koçan püskülü çıkışından itibaren 3. günde hasat edilmiştir, bunun körpe koçan boyları arasında farkın çıkmamasının nedeni olduğu düşünülmektedir. Körpe koçan sayısı ve verimi ise bitki sıklığının artışına bağlı olarak yükselmiştir. Ocağa 1 ve 2 tohum ekilen tüm bitkiler koçan bağlarken, 3 ve 4 tohum ekiminde koçan bağlamayan bitkiler olmuş, fakat 5 ve 6 tohum ekilen parsellerde koçan bağlamayan bitkilerin sayısı daha yüksek olmuştur. Kontrole göre; koçan sayısındaki artış, 6 tohum ekilen parsellerde yaklaşık 3 katı dolayında olmuştur. Najeeb ve ark. (2011) körpe koçan veriminin 11.5-12.0 ton ha-1 olduğunu ve en önemli körpe koçan üreticisi olan Tayland'da 8.0 ton/ha olduğunu, Gözübenli ve Konuşkan (2009) farklı mısır çeşitlerinde ortalama körpe koçan veriminin 208.3$276.5 \mathrm{~kg} \mathrm{da}^{-1}$ arasında değiștiğini, Kara ve ark. (2017) Isparta koşullarında körpe koçan veriminin 118.4-128.0 kg da-1, aynı koşularda başka bir çalışmada körpe koçan sayısı ve veriminin sırasıyla, 8086.4-8457.9 adet $\mathrm{da}^{-1}$ ve 130.54-266.69 $\mathrm{kg} \mathrm{da}^{-1}$ (Kara ve Bozkurt, 2018) arasında değiștiğini bildirmişlerdir.

Çizelge 2. Ocakta tohum sayısının körpe koçan verimine ve özelliklerine etkisi

\begin{tabular}{|c|c|c|c|c|c|c|c|c|}
\hline \multirow{2}{*}{$\begin{array}{c}\text { Ocakta } \\
\text { tohum sayısı } \\
\text { (adet) }\end{array}$} & \multicolumn{2}{|c|}{ Körpe koçan boyu (cm) } & \multicolumn{2}{|c|}{ Körpe koçan çapı (mm) } & \multicolumn{2}{|c|}{$\begin{array}{l}\text { Körpe koçan sayısı } \\
(\text { koçan da-1) }\end{array}$} & \multicolumn{2}{|c|}{$\begin{array}{c}\text { Körpe koçan verimi } \\
\left(\mathrm{kg} \mathrm{da}^{-1}\right)\end{array}$} \\
\hline & 2017 & 2018 & 2017 & 2018 & 2017 & 2018 & 2017 & 2018 \\
\hline 1 Tohum & 11.60 & 11.45 & $15.10 \mathrm{a}$ & 14.45 & $8573.3 \mathrm{f}$ & $9050.7 \mathrm{~d}$ & $167.50 \mathrm{f}$ & $176.1 \mathrm{f}$ \\
\hline $2 "$ & 10.96 & 11.07 & $14.67 \mathrm{ab}$ & 14.32 & $16693.3 \mathrm{e}$ & $17380.3 \mathrm{c}$ & $285.91 \mathrm{e}$ & $292.8 \mathrm{e}$ \\
\hline 3 & 11.33 & 10.95 & $14.57 \mathrm{ab}$ & 14.19 & $19790.7 d$ & $19228.3 c$ & $411.87 \mathrm{~d}$ & $401.4 \mathrm{~d}$ \\
\hline $4 "$ & 10.90 & 10.60 & $13.84 \mathrm{bc}$ & 14.11 & $22759.3 c$ & $22329.0 \mathrm{~b}$ & $502.87 \mathrm{c}$ & $535.8 \mathrm{c}$ \\
\hline $5 ”$ & 10.50 & 10.74 & $13.78 \mathrm{bc}$ & 13.34 & $25340.7 \mathrm{~b}$ & 24291.3ab & $553.02 \mathrm{~b}$ & $582.7 \mathrm{~b}$ \\
\hline $6 "$ & 10.06 & 10.41 & $13.46 \mathrm{c}$ & 12.95 & $26492.7 \mathrm{a}$ & $26224.0 \mathrm{a}$ & $593.07 \mathrm{a}$ & $626.8 \mathrm{a}$ \\
\hline Yillar & 10.89 & 10.60 & 14.23 & 13.89 & 19941.6 & 19750.6 & 419.04 & 435.93 \\
\hline $\mathrm{LSD}_{\text {tohum sayı1 } 1}$ & - & - & 0.89 & - & 1130.0 & 2208.4 & 35.68 & 25.43 \\
\hline Kareler ort. & 0.921 & 0.838 & 1.198 & 0.876 & 76180.4 & 113730.9 & 66412.1 & 79640.1 \\
\hline F değeri & 2.17ö.d & $0.39^{\text {ö.d }}$ & 10.03 & 0.48 ö.d & $399.53^{* *}$ & $156.15^{* *}$ & $7.87^{* *}$ & $2558.9^{* *}$ \\
\hline V.K. (\%) & 5.97 & 7.98 & 2.41 & 9.86 & 2.76 & 4.32 & 13.59 & 5.18 \\
\hline
\end{tabular}

**: $\mathrm{P}<0.01$ seviyesinde önemli, ö.d: önemli değil

Sonuç olarak; ocakta tohum sayısının körpe koçan boyuna etkisi olmazken, özellikle birim alan körpe koçan sayısı ve verimi; ocaktaki tohum sayısının artışına bağlı olarak önemli oranda yükselmiştir. En yüksek körpe koşan sayısı ve verimi ocağa 6 tohum ekilen uygulamada belirlenmiștir. Ocağa birden fazla tohum ekilerek birim alandan daha fazla körpe koçan sayısı elde edilebileceği ve ocağa 5-6 tohum ekimi önerilmektedir. Elde edilen tüm körpe koçanlar TAS 1504-2007 kalite sınıflarına göre pazarlanabilir özellikler taşıdığı belirlenmiştir.

\section{Kaynaklar}

Anonim, 2014. Thai Agricultural Standard (TAS 15042007) in Baby Corn. http://www.acfs.go.th/ standard/download/eng/baby_corn.pdf (Erişim tarihi: 10 Haziran 2014).

Bar-Zur A, Saadi H 1990. Prolific Maize Hybrids for Baby Corn. Journal of Horticulture Science, 65: 97-100. 
Bozkurt, H., Kara, B., 2018. Mısırda körpe koçan kalite sınıflarına ve besin içeriğine hasat zamanlarının etkisi. Türk Tarım ve Doğa Bilimleri Dergisi, 5(1): 1-6.

Gözübenli, H., Konuşkan, Ö., 2009. Farklı bitki sıklıklarının bazı mısır genotiplerinde körpe koçan (baby corn) verimi ve özelliklerine etkisi. Türkiye VIII. Tarla Bitkileri Kongresi, 19-22 Ekim, Poster Bildiriler, s. 573-576, Hatay.

Hooda, S., Kawatra, A., 2013. Nutritional evaluation of baby corn (Zea mays L.). Nutrition and Food Science, 43(1): 68-73.

Kara, B., Gündüz, A., Işık, C., Şener, A., 2017. Farklı mısır (Zea mays L.) alt türlerinin körpe misır özelliklerinin karşılaştırılması. Uluslararası Tarım ve Yaban Hayatı Bilimleri Dergisi, 3: 95-99.

Kara, B., Bozkurt, H., 2018. Mısırda körpe koçan verim ve özelliklerine hasat zamanlarının etkisi. Derim, 35(1): 61-66.
Kara, B., Gül, H., Dizlek, H., 2018. Şeker mısırda kardeş ve ikinci koçanın koparılmasının taze/körpe koçan verimine ve bazı özelliklerine etkisi. Mediterranean Agricultural Sciences, 31(2): 137-140.

Najeeb, S., Rather, A.G., Sheikh, F.A., Ahanger, M.A., Teli, N.A., 2011. Baby corn (Zea mays L.): A means of crop diversification under temperate conditions of Kashmir. Maize Genetics Cooperation Newsletter Vol. 85.

Satyanarayana, E., 1997. Business Line and the India. Information January 16. 1997.

Wang, Z., 2009. Effect of different schedules of baby corn (Zea mays L.) harvests on baby corn yield, grain yield, and economic profit value. Western Kentucky University, Masters Theses \& Specialist Projects. Paper 131. 